\title{
Axonal Transport and Local Translation of mRNA in Neurodegenerative Diseases
}

\author{
Seiichi Nagano ${ }^{1,2}$ and Toshiyuki Araki* \\ ${ }^{1}$ Department of Neurotherapeutics, Osaka University Graduate School of Medicine, Osaka, Japan, ${ }^{2}$ Department \\ of Peripheral Nervous System Research, National Institute of Neuroscience, National Center of Neurology and Psychiatry, \\ Tokyo, Japan
}

OPEN ACCESS

Edited by:

James N. Sleigh,

University College London,

United Kingdom

Reviewed by:

Alessio Vagnoni,

King's College London,

United Kingdom

Claudia Fallini,

University of Rhode Island,

United States

*Correspondence:

Toshiyuki Araki

taraki@ncnp.go.jp

Specialty section:

This article was submitted to

Brain Disease Mechanisms,

a section of the journal

Frontiers in Molecular Neuroscience

Received: 20 April 2021

Accepted: 25 May 2021

Published: 14 June 2021

Citation:

Nagano S and Araki T (2021)

Axonal Transport and Local

Translation of mRNA

in Neurodegenerative Diseases.

Front. Mol. Neurosci. 14:697973.

doi: 10.3389/fnmol.2021.697973
Since neurons have long neurites including axons, it is crucial for the axons to transport many intracellular substances such as proteins and mitochondria in order to maintain their morphology and function. In addition, mRNAs have also been shown to be transported within axons. RNA-binding proteins form complexes with mRNAs, and regulate transport of the mRNAs to axons, as well as locally translate them into proteins. Local translation of mRNAs actively occurs during the development and damage of neurons, and plays an important role in axon elongation, regeneration, and synapse formation. In recent years, it has been reported that impaired axonal transport and local translation of mRNAs may be involved in the pathogenesis of some neurodegenerative diseases. In this review, we discuss the significance of mRNA axonal transport and their local translation in amyotrophic lateral sclerosis/frontotemporal dementia, spinal muscular atrophy, Alzheimer's disease, and fragile X syndrome.

Keywords: axonal transport, local translation, mRNA, amyotrophic lateral sclerosis, frontotemporal dementia, spinal muscular atrophy, Alzheimer's disease, fragile $X$ syndrome

\section{INTRODUCTION}

Neurodegenerative diseases chronically affect neurons in a specific network of the central or peripheral nervous system. Aging is one of the risk factors for the occurrence of these diseases, and the number of patients is increasing year by year with the increasing elderly population (Heemels, 2016). The detailed etiology of these diseases is still undetermined, and there are currently no curative therapeutics. Therefore, it is extremely important to clarify the pathogenic mechanism of these diseases, and to develop new treatment strategies based on identified mechanisms.

It has been suggested that in some of these neurodegenerative diseases, the function of neurons is impaired due to abnormal aggregation/deposition of the causative proteins inside or outside the neurons. For example, in amyotrophic lateral sclerosis (ALS) and frontotemporal dementia (FTD), changes in the localization of transactive responsive-DNA binding protein 43 (TDP-43) (Arai et al., 2006; Neumann et al., 2006) and fused in sarcoma (FUS) (Kwiatkowski et al., 2009; Vance et al., 2009), as well as formation of inclusion bodies containing these proteins are seen in neurons. It is also known that in some ALS/FTD cases, mRNA and abnormally translated dipeptide repeat protein by repeat-associated non-ATG translation are deposited in neurons due to abnormal expansion of the hexanucleotide repeat sequence in the untranslated region of the C9orf 72 gene (DeJesus-Hernandez et al., 2011; Renton et al., 2011; Mori et al., 2013). Alzheimer's disease is 
characterized by the formation of amyloid plaques from extracellular accumulation of amyloid $\beta$ and neurofibrillary tangles due to aggregation of tau protein in neurons (Serý et al., 2013).

In other neurodegenerative diseases, the pathogenic mechanism is assumed to be due to functional decline or loss of the causative gene. In spinal muscular atrophy (SMA), deletion or missense mutations of the survival of motor neuron 1 (SMN1) gene causes loss of functional SMN protein, resulting in damage of motor neurons (Fallini et al., 2012). In fragile $\mathrm{X}$ syndrome (FXS), abnormal trinucleotide repeat expansion in the untranslated region of the fragile X mental retardation 1 (FMR1) gene reduces fragile $\mathrm{X}$ mental retardation protein (FMRP) production, resulting in autism spectrum-like symptoms (Maurin et al., 2014).

In all of these diseases, it is speculated that impaired axonal transport in neurons, especially axonal transport of mRNAs and local translation in axons, are involved in the pathogenesis. Transport and translation of mRNAs in axons are thought to play an important role in maintaining the viability of neurons (Khalil et al., 2018). This review outlines the physiological significance of axonal transport of mRNAs, and explains the pathogenic mechanism of neurodegenerative diseases due to its disruption by providing examples of typical diseases.

\section{PHYSIOLOGICAL ROLE OF MRNA TRANSPORT IN NEURONAL AXONS}

Neurons have neurites consisting of axons and dendrites, which are morphological features characterizing neurons apart from other cells. At the tip of the axon, a growth cone exists during the development of neurons. After maturation, a pre-synapse structure is made to form synapses with other neurons or effector receptors to support to mutual communication. In order to maintain its morphology and function, neurons constantly transport proteins involved in cytoskeleton and synapse formation or essential intracellular substances, such as mitochondria to neurites (Hirokawa et al., 2009). The transport is actively carried out during neurogenesis and regeneration after neuronal injury for axonal elongation/branching and formation of growth cones/synapses. In addition, the transport is also necessary to maintain normal functions in mature neurons.

In recent years, it has been shown that mRNAs are also transported to axons and locally translated onsite into proteins to maintain axonal morphology and function (Holt et al., 2019). Two types of axonal transport are known: fast axonal transport (50-400 $\mathrm{mm} /$ day) and slow axonal transport $(<8 \mathrm{~mm} /$ day). Generally, organelles such as mitochondria are carried by fast axonal transport, whereas cytoskeletal proteins and some soluble proteins are moved via slow transport (Maday et al., 2014). However, even the fast axonal transport is not sufficient for neuronal functions, including synaptic neogenesis or remodeling during long-term potentiation, axonal regeneration after neuronal injury. To enable immediate protein supply at the axon terminal, mRNAs may need to be transported and stored in axons in advance, then locally translated into proteins when necessary.

It is known that factors necessary for protein translation, such as ribosomes, tRNAs, and translation initiation factors are all localized within axons (Kar et al., 2013), and that these translation apparatuses work together to perform local translation. When brain-derived neurotrophic factor (BDNF) or netrin-1, which promotes axon elongation, growth cone and synapse formation, and remodeling, is applied to the axons of cultured neurons, local protein synthesis increases, suggesting that local translation is an important factor in these phenomena (Cagnetta et al., 2018). BDNF binds to its receptor, tropomyosinrelated kinase B (TrkB) and activates various intracellular signaling cascades to release mRNAs from RNA granules and promote their local translation (Leal et al., 2014). Deleted in colorectal carcinoma (DCC), a receptor for netrin-1, binds to translation initiation factors and ribosomes directly inside cells, and then promotes local translation in axons by signaling netrin1 (Tcherkezian et al., 2010).

Ribosomes in axons were originally considered to be transported from cell bodies in neurons or other cells, such as glial cells, after being assembled in the nucleolus (Court et al., 2008). However, it has recently been reported that some ribosomes are assembled in axons in order to maintain their function, from locally translated components such as ribosome proteins as described later (Shigeoka et al., 2019; Nagano et al., 2020). It is thought that neurons have a translation control mechanism specialized for axons, other than the one in cell bodies.

Vesicles, such as endosomes and lysosomes, and mitochondria are crucial to maintain local translation in axons. RNA granules are transferred to axons on lysosomes tethered by annexin A11 (ANXA11), an RNA granule-associated phosphoinositidebinding protein (Liao et al., 2019). Mitochondria are recruited to branching sites of axons following translational machinery to provide energy supply for local translation (Spillane et al., 2013). Furthermore, late endosomes regulate overall protein synthesis in axons by association with both RNA granules and ribosomes, and by controlling mitochondrial function through translation of the related mRNAs (Cioni et al., 2019).

\section{SIGNIFICANCE OF AXONAL DEGENERATION IN NEURODEGENERATIVE DISEASES}

It is controversial which is more critical for triggering neuronal cell death in neurodegenerative diseases: changes in neuronal cell bodies (neuronopathy) or changes in axons (axonopathy). Nonetheless, there are many reports that indicate changes in axons or synapses occur during the early stage of the diseases. In ALS and SMA, morphological and functional abnormalities of the neuromuscular junctions between lower motor neurons and skeletal muscles, are detected in model mice that have not yet developed motor symptoms, as well as in patients with mild symptoms (Fallini et al., 2012; Moloney et al., 2014). In Alzheimer's disease (AD), abnormally aggregated $\mathrm{A} \beta$ oligomers 
inside and outside of neurons have been shown to suppress long-term potentiation at synapses or alter the synaptic structure (Viola and Klein, 2015). In addition, changes suggestive of impaired axonal transport, such as axonal swelling and tau deposition in axons, have been observed in pre-symptomatic model mice and early symptomatic patients (Stokin et al., 2005).

\section{MRNA TRANSPORT AND LOCAL TRANSLATION IN AXONS IN NEURODEGENERATIVE DISEASES}

As mentioned above, local translation in axons plays an important role in maintaining a healthy state of neurons. Therefore, it is presumed that if the local translation is disrupted, the function and viability of neurons will be impaired. In fact, several neurodegenerative diseases have been suggested to impair the local translation function, and are considered to be involved in the pathophysiology of various neurodegenerative disease models. In the following, we review dysfunctions of local translation in some typical neurodegenerative diseases.

\section{Amyotrophic Lateral Sclerosis/Frontotemporal Dementia}

Amyotrophic lateral sclerosis is an intractable disease in which impairment of upper and lower motor neurons cause muscle weakness and atrophy of skeletal muscles throughout the body. FTD is accompanied with personality changes, behavioral abnormalities, aphasia, etc., due to degeneration of cerebral cortical neurons in the frontal and temporal lobes. Mutations of causative genes, especially those of RNA-binding proteins, have been identified in some cases of these diseases, including TDP43 (TARDBP), FUS, heterogeneous nuclear ribonucleoprotein A1 ( $h n R N P A 1), h n R N P A 2 / B 1$. As a frequent mutation in ALS/FTD, abnormal expansion of the GGGGCC repeat sequence in the untranslated region of the C9orf72 gene is also observed (Mejzini et al., 2019).

In addition to the cases caused by these gene mutations, many sporadic ALS/FTD cases of unknown genetic factors show TDP43 disappearance from the nuclei and abnormal depositions in the cytoplasm of neurons, indicating that these diseases form a common pathological spectrum in terms of TDP-43 pathology (Arai et al., 2006; Neumann et al., 2006). Similar localization abnormalities are also observed in other RNA-binding proteins such as FUS (Kwiatkowski et al., 2009; Vance et al., 2009). These phenomena imply that disturbance of RNA metabolism due to functional abnormality of RNA-binding proteins is involved in the pathogenesis of ALS/FTD.

Physiologically, TDP-43 and FUS are mainly localized in the nucleus and control gene translation and splicing of transcribed pre-mRNAs. In addition, these proteins shuttle between the nucleus and cytoplasm to regulate export out of the nucleus, transfer into the cytoplasm, and translation of mature mRNAs (Ederle and Dormann, 2017).

mRNAs can form granular structures in the cytoplasm called RNA granules in association with RNA-binding proteins
(Khalil et al., 2018). mRNAs are transferred to a required site in RNA granules where translation is suppressed, and when protein synthesis is needed, they are released from the RNA granules and incorporated into translation machinery, such as ribosomes. RNA granules consist of: stress granules that temporarily suppress the translation of mRNAs during stress such as starvation, P-bodies that work to degrade mRNAs, and neuronal RNA granules that transport mRNAs to neurites such as axons and dendrites (Anderson and Kedersha, 2009). These RNA granules contain common RNA-binding proteins and are supposed to have similar structures to each other. A single RNA granule includes multiple RNA-binding proteins to incorporate specific mRNA having an affinity for these proteins.

Transactive responsive-DNA binding protein 43 and FUS are constituents of stress granules, which regulate the translation of mRNAs (Aulas and Vande Velde, 2015). In addition, these proteins also form neuronal RNA granules and are involved in the transport of mRNAs to axons (Alami et al., 2014; LópezErauskin et al., 2018). Both TDP-43 and FUS have a highly hydrophobic amino acid sequence region called low complexity domain (LCD), and multiple molecules of RNA-binding proteins associate with this region to form a non-membranous structure called a liquid droplet. It generates surfaced vesicles and contributes to the formation of RNA granules. Most of the TARDBP and FUS gene mutations found in familial ALS/FTD are distributed in the LCD of TDP-43, and in the nuclear localization signal (NLS) site required for nuclear localization of FUS. These mutations are thought to be involved in diseases by changing the intracellular localization and enhancing aggregation of the proteins. Mutant TDP-43 and FUS show disturbance of stress granule dynamics (Aulas and Vande Velde, 2015). In addition, neuronal RNA granules containing TDP-43 dynamically change in morphology and assembly in axons, and the number of mature granules decreases by inhibition of hydrophobic binding (Gopal et al., 2017). It has also been reported that in mutant TDP-43 the neuronal RNA granules formed are unstable, and anterograde axonal transport is reduced (Alami et al., 2014).

Previous reports have identified some molecules to be TDP43-dependent for axonal transport. For instance, neurofilament$\mathrm{L}(N E F L)$ and microtubule associated protein 1B (MAP1B) mRNAs are reported to be transported to axons by TDP-43 (Godena et al., 2011; Alami et al., 2014). Drosophila lacking the TDP-43 gene show abnormal synaptic structure due to a decrease in MAP1B protein at synapses (Coyne et al., 2014). FUS transports FOSB mRNA in axons, dysregulation of which causes abnormal axonal branching (Akiyama et al., 2019). It has also been shown that TDP-43 and FUS transport mRNAs to neurites by binding to a three-dimensional structure called G-quadruplex (Ishiguro et al., 2016; Imperatore et al., 2020). In order to survey target mRNAs for axonal transport by TDP-43, we screened mRNAs downregulated in axons by RNAi-mediated TDP-43 down-regulation, and identified mRNAs of translationrelated factors including multiple cytoplasmic ribosomal proteins and some translation elongation factors as a major targets of TDP-43-dependent axonal transport (Nagano et al., 2020).

Ribosomal proteins compose ribosomes, which are intracellular apparatuses that together with ribosomal RNA 
translate proteins from mRNAs. mRNAs of translation-related proteins, including different subunits of ribosomal proteins, are abundant in neuronal axons (Bigler et al., 2017; Rotem et al., 2017), suggesting that the axonal transport of the mRNAs has functional significance. Ribosomal protein mRNAs have been shown to be translated in axons and to play an important role in axonal ribosome assembly (Shigeoka et al., 2019; Nagano et al., 2020). From the results above, it is conceivable that the impairment of axonal protein translation by decreased axonal transport of ribosomal protein mRNAs may lead to the degeneration of motor neurons in ALD/FTD. Furthermore, we have found that the RNA-binding protein La, which is a known antigen of autoantibodies detected in systemic lupus erythematosus and Sjögren's syndrome (Maraia et al., 2017), is co-localized with TDP-43 and ribosomal protein mRNA in axons. A detailed analysis of the regulatory mechanism of local translation by TDP-43 and $\mathrm{La}$ is anticipated.

Recent reports have shown findings similar to our study. Ribosomal protein mRNAs have been identified as mRNAs with decreased stability in fibroblasts and iPS cell-derived motor neurons in sporadic and C9orf72 mutated ALS patients (Tank et al., 2018). Briese et al. (2020) showed that mRNAs of translation-related proteins including ribosomal proteins are identified as targets for TDP-43-dependent axonal transport in motor neurons, and TDP-43 regulates their local translation. Other reports also showed that mice overexpressing TDP-43 localized in the cytoplasm or mutant FUS have a decrease in overall protein translation in neurons including axons, postulating their involvement in the pathogenesis of ALS/FTD (López-Erauskin et al., 2018; Charif et al., 2020).

Approximately half of FTD cases do not show TDP43 pathology, but instead such cases tau shows abnormal phosphorylation (Šimić et al., 2016). Also, mutations in the tau (MAPT) gene have been identified in juvenile FTD (Hutton et al., 1998). Tau binds to cytoskeletal protein microtubules and contributes to the morphology maintenance of neurons including axons. Abnormally phosphorylated tau undergoes structural changes that reduce its binding to microtubules, and form aggregates and deposits in somatodendritic or axonal compartments (Combs et al., 2019). Microtubules serve as tracks for axonal transport via motor proteins such as kinesin. Therefore, in tauopathy, it is possible that axonal transport of various molecules, including mRNAs, is impaired, which likely disrupts local translation.

\section{Spinal Muscular Atrophy}

Spinal muscular atrophy is a hereditary disorder that causes degeneration of lower motor neurons (Bharucha-Goebel and Kaufmann, 2017). It is classified into types I thru IV according to the age of onset; and the earlier the onset is, the more serious motor symptoms manifest. Pathologically, a decrease in motor neuron axons and morphological changes in the neuromuscular junction are observed at an early stage (Ling et al., 2012; Courtney et al., 2019), and axonal degeneration plays a central role in disease progression. In most SMA cases, deletion of the SMN1 gene destabilizes its translation product SMN, causing a deficiency in SMN protein expression (Fallini et al., 2012). SMN2 gene is a paralog of SMN1 gene, and SMN2 differs from SMN1 by only five nucleotides at the $3^{\prime}$ end of the gene. Most SMN2 transcripts are spliced to skip exon 7 due to a single nucleotide change from SMN1 in the exon. By that, only about $10 \%$ are the full-length transcript to produce a stable protein. The copy number of the SMN2 gene varies between patients. Most severe type I patients have only 1 or 2 copies of SMN2; and the symptoms become milder with an increase of SMN2 copy number because the SMN2 gene transcript can help supplement the deficiency of SMN protein to some extent (Calucho et al., 2018).

Survival of motor neuron is ubiquitously expressed throughout the body, but SMA has a particularly profound effect on lower motor neurons. SMN is mostly located in the nucleus and together with gem-associated proteins (Gemins) assembles small nuclear ribonucleoproteins (snRNP) (Fallini et al., 2012) and forms a complex called spliceosome, which executes pre-mRNA splicing (Pellizzoni, 2007). SMN is also localized in axons (Todd et al., 2010) and regulates axonal transport of mRNAs, as well as their translation by interacting with cytoskeletal proteins and RNA-binding proteins (Fallini et al., 2012). SMN binds to actin-binding proteins profilins, and modulates actin polymerization (Giesemann et al., 1999; Sharma et al., 2005). SMN in axons forms a ribonucleoprotein complex with components different from snRNP, suggesting that SMN have a function independent of splicing regulation in snRNP (Fallini et al., 2011). HuD, the neuron-specific RNA-binding protein assembled into RNA granules, controls axonal transport of mRNAs and axon elongation in cooperation with SMN (Akten et al., 2011; Hao le et al., 2017). In addition, it has been reported that axons have a short isoform different from the canonical SMN which acts on polarity formation in neurons (Pletto et al., 2018). The dysfunction of the molecules may define specific changes in motor neurons due to SMN1 expression deficiency.

Localization of $\beta$-actin $(A C T B)$ mRNA is reduced in axons of SMN-deficient motor neurons (Rossoll et al., 2003). $\beta$-actin is a major skeletal protein that acts on morphological maintenance and dynamics of growth cones and synapses. In addition to axonal targeting of $A C T B$ mRNA, SMN also regulates its local translation in growth cones, which is known to be impaired in SMN-deficient motor neurons (Rossoll et al., 2003; Rathod et al., 2012).

Growth-associated protein 43 (GAP43) mRNA is also transported and translated in axons under the control of SMN (Fallini et al., 2016). GAP43 is highly expressed in growth cones and binds to phospholipids in the cell membrane. This protein signals to maintain cytoskeletal morphology (Hartl and Schneider, 2019). Axonal transport of GAP43 and ACTB mRNAs influence each other, and their local translation affects axon elongation and branching, respectively (Donnelly et al., 2013).

Candidate plasticity-related gene 15 (CPG15) is highly expressed in developing spinal motor neurons, and promotes axon branching and neuromuscular junction formation. CPG15 mRNA is transported to axons with the assistance of SMN and translated locally. Overexpression of CPG15 mRNA rescues SMN deficiency motor axon defects, indicating that localization of CPG15 mRNA in axons is an important determinant of axon architecture (Akten et al., 2011). 
There are other RNA-binding proteins as well, which function in conjunction with SMN. Heterogeneous nuclear ribonucleoprotein $\mathrm{R}$ (hnRNP R) binds to both ACTB mRNA and SMN (Glinka et al., 2010). Furthermore, HuD is involved in axonal transport of GAP43 and CPG15 mRNAs (Akten et al., 2011; Hao le et al., 2017). These RNA-binding proteins are thought to regulate the axonal transport and translation of target mRNAs in cooperation with SMN.

Decreased expression of SMN has been shown to result in reduced overall translation in growth cones (Fallini et al., 2016). This may suggest that the axonal transport and local translation of mRNA regulated by SMN are involved not only in the above-mentioned mRNAs, but also in the metabolic regulation of many mRNAs, or that mRNAs that directly affect the translation function.

\section{Other Neurodegenerative Diseases}

Alzheimer's disease causes memory deficits, behavioral changes, and personality changes due to cognitive impairment, and is the most common causative disease of dementia. Pathologically, amyloid $\beta(A \beta)$ is produced by processing from amyloid precursor protein (APP) and extracellularly deposited as amyloid plaques. These plaques and hyperphosphorylated tau which is characterized by intracellular accumulation as neurofibrillary tangles are hallmarks of the disease (Serý et al., 2013). One of the $A \beta$ isoforms, $A \beta_{1-42}$, has the most potent aggregating property. Mutations in APP, presenilin 1 (PSEN1) and PSEN2 genes have been identified in familial $A D$ patients, and these mutations are responsible for increased processing of $\mathrm{A} \beta_{1-42}$ (Selkoe and Hardy, 2016).

Brain-derived neurotrophic factor $\mathrm{mRNA}$ and BDNF protein are reduced in the brains of $\mathrm{AD}$ patients and model mice (Tanila, 2017). In vitro, $\mathrm{A} \beta$ reduces $\mathrm{BDNF}$ signaling by inhibiting the proteolytic production of BDNF from pro-BDNF
(Zheng et al., 2010), and by suppressing the retrograde axonal transport of the BDNF-TrkB complex (Poon et al., 2013).

On the other hand, local treatment of $A \beta_{1-42}$ on axons has been shown to increase translation from some of the mRNAs within axons (Baleriola et al., 2014). Among them, the transcription factor ATF4 mRNA is locally translated in axons, and then ATF4 protein is retrogradely transported into the nucleus to increase the expression of C/EBP homologous protein (CHOP), a key molecule of the unfolded protein response pathway, thereby causing neurodegeneration. ATF4 mRNA and protein are both increased in axons of brain lesions in patients with $A D$, supporting the notion obtained from cultured neuron experiments.

Furthermore, tau binds to TIA1, one of the RNA-binding proteins in stress granules, and in doing so controls the formation of stress granules and regulates protein translation. Conversely, TIA1 promotes tau aggregation and neurotoxicity (Vanderweyde et al., 2016). In addition, increased expression of G3BP1 and IMP1, which are RNA-binding proteins that bind to MAPT mRNA, change the isoform expression pattern of MAPT mRNA and protein, increase the formation of neuronal RNA granules, and promote axonal elongation (Moschner et al., 2014).

It is also known that TDP-43 pathology exists in $20-50 \%$ of AD patients (Chang et al., 2016). Although it is not yet clear how this change is involved in the pathogenesis of $\mathrm{AD}$, it is quite possible that the dysfunction of TDP-43 is modifying the AD pathology by impairing local translation in neurons with a mechanism similar to ALS/FTD disease models.

Fragile $\mathrm{X}$ syndrome is a disease that causes various physical abnormalities, intellectual disability, and psychiatric symptoms. Abnormal expansion of the CGG repeat sequence in the $5^{\prime}$ untranslated region of the FMR1 gene causes methylation of the promoter of the gene, which decreases the expression of the

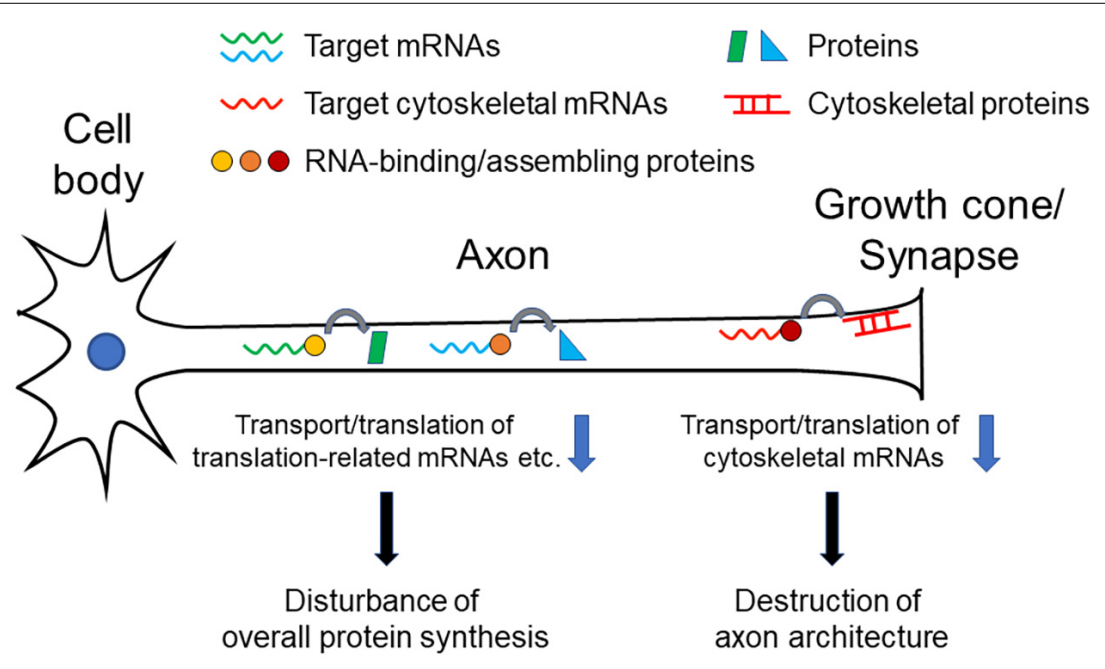

FIGURE 1 | Pathogenetic model of neurodegenerative diseases. Decrease in transport/translation of cytoskeleton-related mRNAs results in inhibiting maintenance of structural integrity of axons, especially of growth cone or synapses, leading neuronal dysfunction and degeneration. Decrease of transport/translation of translation-related (e.g., ribosomal protein mRNAs) mRNAs or many target mRNAs causes dysregulation of overall protein synthesis in axons, which leads neuronal dysfunction and degeneration. 
FMRP at the transcription level for emergence of the disease (Hagerman et al., 2017).

Fragile $\mathrm{X}$ mental retardation protein is an RNA-binding protein having a ribonucleoprotein $\mathrm{K}$ homology $(\mathrm{KH})$ domain and an arginine-glycine-glycine repeat (RGG) domain, which function to suppress the overall translation of proteins via binding to the RGG domain to G-quadruplexes of mRNAs (Schaeffer et al., 2001), or binding to ribosomes between large and small subunits (Chen et al., 2014).

The mechanism of translation suppression by FMRP has been vigorously investigated primarily in dendrites, specifically in postsynaptic spines (Thelen and Kye, 2020; Lu et al., 2021). However, FMRP is also present in axons and forms a complex with molecules involved in RNA interference (RNAi) such as Dicer, and suppresses the expression of RHOA mRNA in distal axons, which causes collapse of growth cones (Hengst et al., 2006). It has also been shown that FMRP transports MAP1B and calmodulin (CALM1) mRNA into axons, and regulates their local translation via microRNA to act on axon elongation (Wang et al., 2015).

\section{General View}

As we overviewed here, different RNA-binding or RNAassembly protein abnormalities are reported to be associated with neurodegenerative disorders, and the corresponding target mRNAs have been identified in each of the proteins. Notably, many of the target mRNAs are cytoskeleton-related protein transcripts that reside in growth cones and synapses. These data suggest that axonal transport and local translation of these mRNAs are important for the morphological and functional formation and maintenance of growth cones and synapses. Dysfunction of the transport and translation of these mRNAs causes degeneration of axon terminals, which disconnects the neural network to cause symptoms of each disease (Figure 1).

\section{REFERENCES}

Akiyama, T., Suzuki, N., Ishikawa, M., Fujimori, K., Sone, T., Kawada, J., et al. (2019). Aberrant axon branching via Fos-B dysregulation in FUS-ALS motor neurons. EBioMedicine 45, 362-378. doi: 10.1016/j.ebiom.2019.06.013

Akten, B., Kye, M. J., Hao le, T., Wertz, M. H., Singh, S., Nie, D., et al. (2011). Interaction of survival of motor neuron (SMN) and HuD proteins with mRNA cpg15 rescues motor neuron axonal deficits. Proc. Natl. Acad. Sci. U.S.A. 108, 10337-10342. doi: 10.1073/pnas.1104928108

Alami, N. H., Smith, R. B., Carrasco, M. A., Williams, L. A., Winborn, C. S., Han, S. S. W., et al. (2014). Axonal transport of TDP-43 mRNA granules is impaired by ALS-causing mutations. Neuron 81, 536-543. doi: 10.1016/j.neuron.2013. 12.018

Al-Chalabi, A., Andersen, P. M., Nilsson, P., Chioza, B., Andersson, J. L., Russ, C., et al. (1999). Deletions of the heavy neurofilament subunit tail in amyotrophic lateral sclerosis. Hum. Mol. Genet. 8, 157-164. doi: 10.1093/hmg/8. 2.157

Anderson, P., and Kedersha, N. (2009). RNA granules: post-transcriptional and epigenetic modulators of gene expression. Nat. Rev. Mol. Cell Biol. 10, 430-436. doi: $10.1038 / \mathrm{nrm} 2694$

Arai, T., Hasegawa, M., Akiyama, H., Ikeda, K., Nonaka, T., Mori, H., et al. (2006). TDP-43 is a component of ubiquitin-positive tau-negative inclusions in frontotemporal lobar degeneration and amyotrophic lateral sclerosis. Biochem. Biophys. Res. Commun. 351, 602-611. doi: 10.1016/j.bbrc.2006.10.093
Impairment of such functions may also gradually affect neuronal viability, resulting in chronically progressive neurodegeneration. Furthermore, TUBA4A and NEFH are listed as the causative genes of some ALS cases (Al-Chalabi et al., 1999; Smith et al., 2014), which also indicates the importance of cytoskeletal proteins in the pathogenesis of the disease.

The integrity of ribosomes in axons to maintain local protein synthesis capability may also be a critical factor for maintaining neuronal health. As we discussed above, RNAbinding and RNA-assembling proteins can regulate transport and translation of many different mRNAs in axons, rather than limited specific targets. In addition to our finding that TDP-43 targets translation-related mRNAs for axonal transport, change of overall translation efficiency is detected in axons as a result of TDP-43, FUS, and SMN dysfunction (Rossoll et al., 2003; LópezErauskin et al., 2018; Nagano et al., 2020). Protein synthesizing activity in axons and synapses is indispensable not only for rapid neuronal responses, but also for maintaining structural integrity and electrical conductivity of axons (Figure 1).

\section{CONCLUSION}

Axonal transport and local translation of mRNAs play an important role in maintaining the survival of neurons, and their failure to do so is greatly involved in the development of many neurodegenerative diseases. By improving the function of mRNA metabolism in axons, it will be possible to develop new therapeutic strategies for these neurodegenerative diseases.

\section{AUTHOR CONTRIBUTIONS}

SN and TA wrote the manuscript. Both authors contributed to the article and approved the submitted version.

Aulas, A., and Vande Velde, C. (2015). Alterations in stress granule dynamics driven by TDP-43 and FUS: a link to pathological inclusions in ALS? Front. Cell. Neurosci. 9:423. doi: 10.3389/fncel.2015.00423

Baleriola, J., Walker, C. A., Jean, Y. Y., Crary, J. F., Troy, C. M., Nagy, P. L., et al. (2014). Axonally synthesized ATF4 transmits a neurodegenerative signal across brain regions. Cell 158, 1159-1172. doi: 10.1016/j.cell.2014.07.001

Bharucha-Goebel, D., and Kaufmann, P. (2017). Treatment advances in spinal muscular atrophy. Curr. Neurol. Neurosci. Rep. 17:91. doi: 10.1007/s11910-0170798-y

Bigler, R. L., Kamande, J. W., Dumitru, R., Niedringhaus, M., and Taylor, A. M. (2017). Messenger RNAs localized to distal projections of human stem cell derived neurons. Sci. Rep. 7:611. doi: 10.1038/s41598-017-00676-w

Briese, M., Saal-Bauernschubert, L., Lüningschrör, P., Moradi, M., Dombert, B., Surrey, V., et al. (2020). Loss of Tdp-43 disrupts the axonal transcriptome of motoneurons accompanied by impaired axonal translation and mitochondria function. Acta Neuropathol. Commun. 8:116. doi: 10.1186/s40478-020-00987-6

Cagnetta, R., Frese, C. K., Shigeoka, T., Krijgsveld, J., and Holt, C. E. (2018). Rapid cue-specific remodeling of the nascent axonal proteome. Neuron 99, 29-46. doi: 10.1016/j.neuron.2018.06.004

Calucho, M., Bernal, S., Alías, L., March, F., Venceslá, A., Rodríguez-Álvarez, F. J., et al. (2018). Correlation between SMA type and SMN2 copy number revisited: An analysis of 625 unrelated Spanish patients and a compilation of 2834 reported cases. Neuromuscul. Disord. 28, 208-215. doi: 10.1016/j.nmd. 2018.01.003 
Chang, X. L., Tan, M. S., Tan, L., and Yu, J. T. (2016). The role of TDP-43 in Alzheimer's disease. Mol. Neurobiol. 53, 3349-3359. doi: 10.1007/s12035-0159264-5

Charif, S. E., Luchelli, L., Vila, A., Blaustein, M., and Igaz, L. M. (2020). Cytoplasmic expression of the ALS/FTD-related protein TDP-43 decreases global translation both in vitro and in vivo. Front. Cell. Neurosci. 14:594561. doi: 10.3389/fncel. 2020.594561

Chen, E., Sharma, M. R., Shi, X., Agrawal, R. K., and Joseph, S. (2014). Fragile $\mathrm{X}$ mental retardation protein regulates translation by binding directly to the ribosome. Mol. Cell 54, 407-417. doi: 10.1016/j.molcel.2014.03.023

Cioni, J. M., Lin, J. Q., Holtermann, A. V., Koppers, M., Jakobs, M. A. H., Azizi, A., et al. (2019). Late endosomes act as mRNA translation platforms and sustain mitochondria in axons. Cell 176, 56-72. doi: 10.1016/j.cell.2018.11.030

Combs, B., Mueller, R. L., Morfini, G., Brady, S. T., and Kanaan, N. M. (2019). Tau and axonal transport misregulation in tauopathies. Adv. Exp. Med. Biol. 1184, 81-95. doi: 10.1007/978-981-32-9358-8_7

Court, F. A., Hendriks, W. T., MacGillavry, H. D., Alvarez, J., and van Minnen, J. (2008). Schwann cell to axon transfer of ribosomes: toward a novel understanding of the role of glia in the nervous system. J. Neurosci. 28, 11024-11029. doi: 10.1523/JNEUROSCI.2429-08.2008

Courtney, N. L., Mole, A. J., Thomson, A. K., and Murray, L. M. (2019). Reduced P53 levels ameliorate neuromuscular junction loss without affecting motor neuron pathology in a mouse model of spinal muscular atrophy. Cell Death Dis. 10:515. doi: 10.1038/s41419-019-1727-6

Coyne, A. N., Siddegowda, B. B., Estes, P. S., Johannesmeyer, J., Kovalik, T., Daniel, S. G., et al. (2014). Futsch/MAP1B mRNA is a translational target of TDP-43 and is neuroprotective in a Drosophila model of amyotrophic lateral sclerosis. J. Neurosci. 34, 15962-15974. doi: 10.1523/JNEUROSCI.2526-14.2014

DeJesus-Hernandez, M., Mackenzie, I. R., Boeve, B. F., Boxer, A. L., Baker, M., Rutherford, N. J., et al. (2011). Expanded GGGGCC hexanucleotide repeat in noncoding region of C9ORF72 causes chromosome 9p-linked FTD and ALS. Neuron 72, 245-256. doi: 10.1016/j.neuron.2011.09.011

Donnelly, C. J., Park, M., Spillane, M., Yoo, S., Pacheco, A., Gomes, C., et al. (2013). Axonally synthesized $\beta$-actin and GAP-43 proteins support distinct modes of axonal growth. J. Neurosci. 33, 3311-3322. doi: 10.1523/JNEUROSCI.1722-12. 2013

Ederle, H., and Dormann, D. (2017). TDP-43 and FUS en route from the nucleus to the cytoplasm. FEBS Lett. 591, 1489-1507. doi: 10.1002/1873-3468. 12646

Fallini, C., Bassell, G. J., and Rossoll, W. (2012). Spinal muscular atrophy: the role of SMN in axonal mRNA regulation. Brain Res. 1462, 81-92. doi: 10.1016/j. brainres.2012.01.044

Fallini, C., Donlin-Asp, P. G., Rouanet, J. P., Bassell, G. J., and Rossoll, W. (2016). Deficiency of the survival of motor neuron protein impairs mRNA localization and local translation in the growth cone of motor neurons. J. Neurosci. 36, 3811-3820. doi: 10.1523/JNEUROSCI.2396-15.2016

Fallini, C., Zhang, H., Su, Y., Silani, V., Singer, R. H., Rossoll, W., et al. (2011). The survival of motor neuron (SMN) protein interacts with the mRNA-binding protein $\mathrm{HuD}$ and regulates localization of poly(A) mRNA in primary motor neuron axons. J. Neurosci. 31, 3914-3925. doi: 10.1523/JNEUROSCI.3631-10. 2011

Giesemann, T., Rathke-Hartlieb, S., Rothkegel, M., Bartsch, J. W., Buchmeier, S., Jockusch, B. M., et al. (1999). A role for polyproline motifs in the spinal muscular atrophy protein SMN. Profilins bind to and colocalize with smn in nuclear gems. J. Biol. Chem. 274, 37908-37914. doi: 10.1074/jbc.274.53. 37908

Glinka, M., Herrmann, T., Funk, N., Havlicek, S., Rossoll, W., Winkler, C., et al. (2010). The heterogeneous nuclear ribonucleoprotein- $\mathrm{R}$ is necessary for axonal beta-actin mRNA translocation in spinal motor neurons. Hum. Mol. Genet. 19, 1951-1966. doi: 10.1093/hmg/ddq073

Godena, V. K., Romano, G., Romano, M., Appocher, C., Klima, R., Buratti, E., et al. (2011). TDP-43 regulates Drosophila neuromuscular junctions growth by modulating Futsch/MAP1B levels and synaptic microtubules organization. PLoS One 6:e17808. doi: 10.1371/journal.pone.0017808

Gopal, P. P., Nirschl, J. J., Klinman, E., and Holzbaur, E. L. (2017). Amyotrophic lateral sclerosis-linked mutations increase the viscosity of liquid-like TDP-43 RNP granules in neurons. Proc. Natl. Acad. Sci. U.S.A. 114, E2466-E2475. doi: $10.1073 /$ pnas. 1614462114
Hagerman, R. J., Berry-Kravis, E., Hazlett, H. C., Bailey, D. B. Jr., Moine, H., Kooy, R. F., et al. (2017). Fragile X syndrome. Nat. Rev. Dis. Primers 3:17065. doi: $10.1038 /$ nrdp. 2017.65

Hao le, T., Duy, P. Q., An, M., Talbot, J., Iyer, C. C., Wolman, M., et al. (2017). $\mathrm{HuD}$ and the survival motor neuron protein interact in motoneurons and are essential for motoneuron development, function, and mRNA regulation. J. Neurosci. 37, 11559-11571. doi: 10.1523/JNEUROSCI.1528-17.2017

Hartl, M., and Schneider, R. (2019). A unique family of neuronal signaling proteins implicated in oncogenesis and tumor suppression. Front. Oncol. 9:289. doi: 10.3389/fonc.2019.00289

Heemels, M. T. (2016). Neurodegenerative diseases. Nature 539:179. doi: 10.1038/ 539179 a

Hengst, U., Cox, L. J., Macosko, E. Z., and Jaffrey, S. R. (2006). Functional and selective RNA interference in developing axons and growth cones. J. Neurosci. 26, 5727-5732. doi: 10.1523/JNEUROSCI.5229-05.2006

Hirokawa, N., Noda, Y., Tanaka, Y., and Niwa, S. (2009). Kinesin superfamily motor proteins and intracellular transport. Nat. Rev. Mol. Cell Biol. 10, 682-696. doi: $10.1038 / \mathrm{nrm} 2774$

Holt, C. E., Martin, K. C., and Schuman, E. M. (2019). Local translation in neurons: visualization and function. Nat. Struct. Mol. Biol. 26, 557-566. doi: 10.1038/ s41594-019-0263-5

Hutton, M., Lendon, C. L., Rizzu, P., Baker, M., Froelich, S., Houlden, H., et al. (1998). Association of missense and $5^{\prime}$-splice-site mutations in tau with the inherited dementia FTDP-17. Nature 393, 702-705. doi: 10.1038/31508

Imperatore, J. A., McAninch, D. S., Valdez-Sinon, A. N., Bassell, G. J., and Mihailescu, M. R. (2020). FUS recognizes G quadruplex structures within neuronal mRNAs. Front. Mol. Biosci. 7:6. doi: 10.3389/fmolb.2020.00006

Ishiguro, A., Kimura, N., Watanabe, Y., Watanabe, S., and Ishihama, A. (2016). TDP-43 binds and transports G-quadruplex-containing mRNAs into neurites for local translation. Genes Cells 21, 466-481. doi: 10.1111/gtc. 12352

Kar, A. N., MacGibeny, M. A., Gervasi, N. M., Gioio, A. E., and Kaplan, B. B. (2013). Intra-axonal synthesis of eukaryotic translation initiation factors regulates local protein synthesis and axon growth in rat sympathetic neurons. J. Neurosci. 33, 7165-7174. doi: 10.1523/JNEUROSCI.2040-12.2013

Khalil, B., Morderer, D., Price, P. L., Liu, F., and Rossoll, W. (2018). mRNP assembly, axonal transport, and local translation in neurodegenerative diseases. Brain Res. 1693, 75-91. doi: 10.1016/j.brainres.2018.02.018

Kwiatkowski, T. J. Jr., Bosco, D. A., Leclerc, A. L., Tamrazian, E., Vanderburg, C. R., Russ, C., et al. (2009). Mutations in the FUS/TLS gene on chromosome 16 cause familial amyotrophic lateral sclerosis. Science 323, 1205-1208. doi: $10.1126 /$ science. 1166066

Leal, G., Comprido, D., and Duarte, C. B. (2014). BDNF-induced local protein synthesis and synaptic plasticity. Neuropharmacology 76, 639-656. doi: 10.1016/ j.neuropharm.2013.04.005

Liao, Y. C., Fernandopulle, M. S., Wang, G., Choi, H., Hao, L., Drerup, C. M., et al. (2019). RNA granules hitchhike on lysosomes for long-distance transport, using annexin A11 as a molecular tether. Cell 179, 147-164. doi: 10.1016/j.cell.2019. 08.050

Ling, K. K. Y., Gibbs, R. M., Feng, Z., and Ko, C. P. (2012). Severe neuromuscular denervation of clinically relevant muscles in a mouse model of spinal muscular atrophy. Hum. Mol. Genet. 21, 185-195. doi: 10.1093/hmg/ddr453

López-Erauskin, J., Tadokoro, T., Baughn, M. W., Myers, B., McAlonis-Downes, M., Chillon-Marinas, C., et al. (2018). ALS/FTD-linked mutation in FUS suppresses intra-axonal protein synthesis and drives disease without nuclear loss-of-function of FUS. Neuron 100, 816-830. doi: 10.1016/j.neuron.2018. 09.044

Lu, J. X., Wang, Y., Zhang, Y. J., Shen, M. F., Li, H. Y., Yu, Z. Q., et al. (2021). Axonal mRNA localization and local translation in neurodegenerative disease. Neural Regen. Res. 16, 1950-1957. doi: 10.4103/1673-5374.308074

Maday, S., Twelvetrees, A. E., Moughamian, A. J., and Holzbaur, E. L. (2014). Axonal transport: cargo-specific mechanisms of motility and regulation. Neuron 84, 292-309. doi: 10.1016/j.neuron.2014.10.019

Maraia, R. J., Mattijssen, S., Cruz-Gallardo, I., and Conte, M. R. (2017). The La and related RNA-binding proteins (LARPs): structures, functions, and evolving perspectives. Wiley Interdiscip. Rev. RNA 8:e1430. doi: 10.1002/wrna.1430

Maurin, T., Zongaro, S., and Bardoni, B. (2014). Fragile X syndrome: from molecular pathology to therapy. Neurosci. Biobehav. Rev. 46, 242-255. doi: 10.1016/j.neubiorev.2014.01.006 
Mejzini, R., Flynn, L. L., Pitout, I. L., Fletcher, S., Wilton, S. D., and Akkari, P. A. (2019). ALS genetics, mechanisms, and therapeutics: where are we now? Front. Neurosci. 13:1310. doi: 10.3389/fnins.2019.01310

Moloney, E. B., de Winter, F., and Verhaagen, J. (2014). ALS as a distal axonopathy: molecular mechanisms affecting neuromuscular junction stability in the presymptomatic stages of the disease. Front. Neurosci. 8:252. doi: 10.3389/ fnins.2014.00252

Mori, K., Weng, S. M., Arzberger, T., May, S., Rentzsch, K., Kremmer, E., et al. (2013). The C9orf72 GGGGCC repeat is translated into aggregating dipeptiderepeat proteins in FTLD/ALS. Science 339, 1335-1338. doi: 10.1126/science. 1232927

Moschner, K., Sündermann, F., Meyer, H., da Graca, A. P., Appel, N., Paululat, A., et al. (2014). RNA protein granules modulate tau isoform expression and induce neuronal sprouting. J. Biol. Chem. 289, 16814-16825. doi: 10.1074/jbc. M113.541425

Nagano, S., Jinno, J., Abdelhamid, R. F., Jin, Y., Shibata, M., Watanabe, S., et al. (2020). TDP-43 transports ribosomal protein mRNA to regulate axonal local translation in neuronal axons. Acta Neuropathol. 140, 695-713. doi: 10.1007/ s00401-020-02205-y

Neumann, M., Sampathu, D. M., Kwong, L. K., Truax, A. C., Micsenyi, M. C., Chou, T. T., et al. (2006). Ubiquitinated TDP-43 in frontotemporal lobar degeneration and amyotrophic lateral sclerosis. Science 314, 130-133. doi: 10. $1126 /$ science. 1134108

Pellizzoni, L. (2007). Chaperoning ribonucleoprotein biogenesis in health and disease. EMBO Rep. 8, 340-345. doi: 10.1038/sj.embor.7400941

Pletto, D., Capra, S., Finardi, A., Colciaghi, F., Nobili, P., Battaglia, G. S., et al. (2018). Axon outgrowth and neuronal differentiation defects after a-SMN and FL-SMN silencing in primary hippocampal cultures. PLoS One 13:e0199105. doi: 10.1371/journal.pone.0199105

Poon, W. W., Carlos, A. J., Aguilar, B. L., Berchtold, N. C., Kawano, C. K., Zograbyan, V., et al. (2013). $\beta$-Amyloid (A $\beta$ ) oligomers impair brainderived neurotrophic factor retrograde trafficking by down-regulating ubiquitin C-terminal hydrolase, UCH-L1. J. Biol. Chem. 288, 16937-16948. doi: 10.1074/ jbc.M113.463711

Rathod, R., Havlicek, S., Frank, N., Blum, R., and Sendtner, M. (2012). Laminin induced local axonal translation of $\beta$-actin mRNA is impaired in SMN-deficient motoneurons. Histochem. Cell Biol. 138, 737-748. doi: 10.1007/s00418-0120989-1

Renton, A. E., Majounie, E., Waite, A., Simón-Sánchez, J., Rollinson, S., Gibbs, J. R., et al. (2011). A hexanucleotide repeat expansion in C9ORF72 is the cause of chromosome 9p21-linked ALS-FTD. Neuron 72, 257-268. doi: 10.1016/j. neuron.2011.09.010

Rossoll, W., Jablonka, S., Andreassi, C., Kröning, A. K., Karle, K., Monani, U. R., et al. (2003). Smn, the spinal muscular atrophy-determining gene product, modulates axon growth and localization of beta-actin mRNA in growth cones of motoneurons. J. Cell Biol. 163, 801-812. doi: 10.1083/jcb.200304128

Rotem, N., Magen, I., Ionescu, A., Gershoni-Emek, N., Altman, T., Costa, C. J., et al. (2017). ALS along the axons - expression of coding and noncoding RNA differs in axons of ALS models. Sci. Rep. 7:44500. doi: 10.1038/srep44500

Schaeffer, C., Bardoni, B., Mandel, J. L., Ehresmann, B., Ehresmann, C., and Moine, H. (2001). The fragile $\mathrm{X}$ mental retardation protein binds specifically to its mRNA via a purine quartet motif. EMBO J. 20, 4803-4813. doi: 10.1093/emboj/ 20.17.4803

Selkoe, D. J., and Hardy, J. (2016). The amyloid hypothesis of Alzheimer's disease at 25 years. EMBO Mol. Med. 8, 595-608. doi: 10.15252/emmm. 201606210

Serý, O., Povová, J., Míšek, I., Pešák, L., and Janout, V. (2013). Molecular mechanisms of neuropathological changes in Alzheimer's disease: a review. Folia Neuropathol. 51, 1-9. doi: 10.5114/fn.2013.34190

Sharma, A., Lambrechts, A., Hao le, T., Le, T. T., Sewry, C. A., Ampe, C., et al. (2005). A role for complexes of survival of motor neurons (SMN) protein with gemins and profilin in neurite-like cytoplasmic extensions of cultured nerve cells. Exp. Cell Res. 309, 185-197. doi: 10.1016/j.yexcr.2005.05.014
Shigeoka, T., Koppers, M., Wong, H. H., Lin, J. Q., Cagnetta, R., Dwivedy, A., et al. (2019). On-site ribosome remodeling by locally synthesized ribosomal proteins in axons. Cell Rep. 29, 3605-3619. doi: 10.1016/j.celrep.2019.11.025

Šimić, G., Babić Leko, M., Wray, S., Harrington, C., Delalle, I., JovanovMilošević, N., et al. (2016). Tau protein hyperphosphorylation and aggregation in Alzheimer's disease and other tauopathies, and possible neuroprotective strategies. Biomolecules 6:6. doi: 10.3390/biom6010006

Smith, B. N., Ticozzi, N., Fallini, C., Gkazi, A. S., Topp, S., Kenna, K. P., et al. (2014). Exome-wide rare variant analysis identifies TUBA4A mutations associated with familial ALS. Neuron 84, 324-331. doi: 10.1016/j.neuron.2014.09.027

Spillane, M., Ketschek, A., Merianda, T. T., Twiss, J. L., and Gallo, G. (2013). Mitochondria coordinate sites of axon branching through localized intraaxonal protein synthesis. Cell Rep. 5, 1564-1575. doi: 10.1016/j.celrep.2013. 11.022

Stokin, G. B., Lillo, C., Falzone, T. L., Brusch, R. G., Rockenstein, E., Mount, S. L., et al. (2005). Axonopathy and transport deficits early in the pathogenesis of Alzheimer's disease. Science 307, 1282-1288. doi: 10.1126/science.1105681

Tanila, H. (2017). The role of BDNF in Alzheimer's disease. Neurobiol. Dis. 97, 114-118. doi: 10.1016/j.nbd.2016.05.008

Tank, E. M., Figueroa-Romero, C., Hinder, L. M., Bedi, K., Archbold, H. C., Li, X., et al. (2018). Abnormal RNA stability in amyotrophic lateral sclerosis. Nat. Commun. 9:2845. doi: 10.1038/s41467-018-05049-Z

Tcherkezian, J., Brittis, P. A., Thomas, F., Roux, P. P., and Flanagan, J. G. (2010). Transmembrane receptor DCC associates with protein synthesis machinery and regulates translation. Cell 141, 632-644. doi: 10.1016/j.cell.2010.04.008

Thelen, M. P., and Kye, M. J. (2020). The role of RNA binding proteins for local mRNA translation: implications in neurological disorders. Front. Mol. Biosci. 6:161. doi: 10.3389/fmolb.2019.00161

Todd, A. G., Morse, R., Shaw, D. J., Stebbings, H., and Young, P. J. (2010). Analysis of SMN-neurite granules: core cajal body components are absent from SMNcytoplasmic complexes. Biochem. Biophys. Res. Commun. 397, 479-485. doi: 10.1016/j.bbrc.2010.05.139

Vance, C., Rogelj, B., Hortobágyi, T., De Vos, K. J., Nishimura, A. L., Sreedharan, J., et al. (2009). Mutations in FUS, an RNA processing protein, cause familial amyotrophic lateral sclerosis type 6. Science 323, 1208-1211. doi: 10.1126/ science. 1165942

Vanderweyde, T., Apicco, D. J., Youmans-Kidder, K., Ash, P. E. A., Cook, C., Lummertz da Rocha, E., et al. (2016). Interaction of tau with the RNAbinding protein TIA1 regulates tau pathophysiology and toxicity. Cell Rep. 15, 1455-1466. doi: 10.1016/j.celrep.2016.04.045

Viola, K. L., and Klein, W. L. (2015). Amyloid $\beta$ oligomers in Alzheimer's disease pathogenesis, treatment, and diagnosis. Acta Neuropathol. 129, 183-206. doi: 10.1007/s00401-015-1386-3

Wang, B., Pan, L., Wei, M., Wang, Q., Liu, W. W., Wang, N., et al. (2015). FMRPmediated axonal delivery of miR-181d regulates axon elongation by locally targeting Map1b and Calm1. Cell Rep. 13, 2794-2807. doi: 10.1016/j.celrep. 2015.11.057

Zheng, Z., Sabirzhanov, B., and Keifer, J. (2010). Oligomeric amyloid- $\beta$ inhibits the proteolytic conversion of brain-derived neurotrophic factor (BDNF), AMPA receptor trafficking, and classical conditioning. J. Biol. Chem. 285, 34708-34717. doi: 10.1074/jbc.M110.150821

Conflict of Interest: The authors declare that the research was conducted in the absence of any commercial or financial relationships that could be construed as a potential conflict of interest.

Copyright (c) 2021 Nagano and Araki. This is an open-access article distributed under the terms of the Creative Commons Attribution License (CC BY). The use, distribution or reproduction in other forums is permitted, provided the original author(s) and the copyright owner(s) are credited and that the original publication in this journal is cited, in accordance with accepted academic practice. No use, distribution or reproduction is permitted which does not comply with these terms. 